\title{
Feasibility study and control values of transient elastography in healthy children
}

\author{
Guido Engelmann • Ulrike Teufel • Georg F. Hoffmann
}

Received: 31 May 2012 / Accepted: 11 June 2012 / Published online: 23 June 2012

(C) Springer-Verlag 2012

We are thankful to Ferraioli et al. for their commentary but do not share the opinion that a severe bias limits the results of our study. The $\mathrm{S}$ and $\mathrm{M}$ probes were used according to the manufacturer's recommendations. Our main goal was to produce pediatric reference values for the upper limit of normal (ULN). In clinical practice, people will use the probe that is recommended for the thoracic circumference and might find our data useful for evaluation of the data obtained with the appropriate probe.

We know that different probes in adult patients can lead to different results in terms of liver stiffness measurement (LSM) due to different depths of measurement, etc. We agree that there is room for speculation whether or not the absolute value of LSM may be comparable between S and $M$ probes and if our finding of increasing LSM with age might therefore be partially overinterpreted over the period of 18 years. However, the same increase could also be clearly demonstrated in patients who were only scanned with the $\mathrm{S}$ probe (patients from 0 to 11 years of age; only two patients were scanned with the $\mathrm{M}$ probe). The M group in itself also demonstrated this increase and ended up in the range of adult studies.

It would be very interesting to analyze whether in the prepubertal patients $\mathrm{M}$ and $\mathrm{S}$ probes would give the same results or not. This aspect should be addressed in future studies on TE in children. 